\title{
Contribuição técnico-científica ao aprimoramento do marco regulatório visando à proteção do Pantanal Mato-grossense
}

\author{
Carlos Teodoro J. Hugueney Irigaray
}

Professor Associado da UFMT e do CPP. Doutor em Direito pela UFSC. Pós-doutorado junto ao Center for Latin America Studies-UFL (EUA), coordenador da Clínica de Direitos Humanos e Meio Ambiente e Meio Ambiente da UFMT.

Carolina Joana da Silva

Professora adjunta da Unemat. Coordenadora do doutorado em Biodiversidade e Biotecnologia - Rede Bionorte em MT. Professora do Programa de Pós-Graduação em Ciências Ambientais e do doutorado em Biodiversidade e Biotecnologia.

Cátia Nunes da Cunha

Professora titular da UFMT e pesquisadora associada ao CPP. Doutora em Ecologia e Recursos Naturais pela UFSCar. Pós-doutorado em Ecologia de Áreas Úmidas no Max-

Planck Institut für Limnology, Alemanha, membro do Science Wetland Society, do Global Wetland Consortium e do INAU.

Débora F. Calheiros

Bióloga com doutorado em Ciências pelo CENA/USP, pesquisadora da Embrapa Pantanal cedida ao Instituto de Saúde Coletiva/UFMT. Atua nas áreas de políticas públicas em recursos hídricos, em especial no Sistema Bacia do Alto Paraguai.

Pierre Girard

Professor de Hidro-ecologia da UFMT e pesquisador associado ao CPP. Sua pesquisa enfoca impactos das hidroelétricas e da mudança climática, principalmente no Pantanal. Colabora com a Universidade do Québec (Canadá) e com o Ministério Público Estadual (MT) sobre recursos hídricos.

\section{Wolfgang Johannes Junk}

Doutor em Zoologia, Botânica, Química, Oceanografia e Limnologia pela Universidade de Kiel (Christian-Albrechts Universität). Livre-docente em Ecologia Tropical e pesquisador sênior e líder do Grupo Ecologia Tropical no Instituto Max Planck para Limnologia em Plioen, Alemanha. Coordenador cientifico do INAU.

Sumário: 1. Nota Técnica; 2. Proposta de Substitutivo ao Projeto de Lei do Senado $n^{\circ}$ 750, de 2011; 3. Considerações finais; 4. Referências. 


\section{Nota Técnica}

Dada a importância ecológica do Pantanal Mato-grossense, sua riqueza em biodiversidade, beleza cênica e diversidade cultural, a Clínica de Direitos Humanos e Meio Ambiente da UFMT se soma a outras instituições de pesquisa no esforço de contribuir, com subsídios técnico-cientificos, com a formulação de políticas públicas visando à conservação e uso sustentável dessa grande área úmida que se constitui em "santuário ecológico", reconhecido como Patrimônio Nacional (CF art. $225 \S 4^{\circ}$ ), Patrimônio Mundial da Humanidade, Reserva da Biosfera e Sítio Ramsar.

Ressalte-se que, a despeito da expressa previsão constitucional, esse conjunto de ecossistemas, à semelhança das demais áreas úmidas existentes no Brasil, segue legalmente desprotegido e enfrenta alguns desafios para sua conservação.

Ou seja, apesar de a Constituição Federal exigir uma proteção diferenciada para o Pantanal, não existe qualquer legislação federal que estabeleça, de forma sistêmica, e integrada, normas para sua utilização sustentável, considerando-o como uma unidade físico-territorial, assim como não existem ações políticas consistentes para enfrentar alguns desafios que colocam em risco essa importante área úmida.

Dentre os desafios que se apresentam para a conservação do Pantanal, está o fato de que não se considera na gestão (limitada por escassos recursos humanos e materiais) a bacia hidrográfica enquanto unidade territorial para implementação de uma política que integre a conservação desse conjunto de ecossistemas e a manutenção da qualidade dos corpos hídricos que o formam, ignorando que os problemas que ocorrem no planalto circundante afetam diretamente a planície inundável.

A supressão da vegetação para uso intensivo do solo no entorno do Pantanal afeta diretamente os rios que drenam para a planície alagável, que sofrem com o assoreamento causando enormes prejuízos socioeconômicos. ${ }^{1}$

De acordo com Irigaray et al.: ${ }^{2}$

Em decorrência do assoreamento, extensas áreas do Pantanal passaram a ficar permanentemente inundadas, causando graves impactos na re-

1 O desastre ocorrido no Rio Taquari, um dos principais afluentes do Rio Paraguai, que transbordou por causa do assoreamento e já inundou permanentemente 1,5 milhão de hectares na sub-região do Paiaguás (nordeste de Corumbá), é emblemático e se repete em menor escala em outros cursos d'água.

2 IRIGARAY, C. T. H.; SILVA, C. J.; MEDEIROS, H. Q.; GIRARD, P.; FAVA, G. C.; MACIEL, J. C.; GALLO, R. L.; NOVAIS, L. G. O Pantanal Matogrossense enquanto patrimônio nacional no contexto das mudanças climáticas. In: SILVA, Solange T.; CUREAU, Sandra; LEUZINGER, M. (Org.). Mudança do Clima. Desafios jurídicos, econômicos e socioambientais. 1. ed. São Paulo: Fiuza, 2011. p. 12. 
gião, que incluem alterações na qualidade da água, mudanças no regime hidrológico, alterações florísticas e fitofisionômicas, e também impactos socioeconômicos, que afetaram sobretudo as populações tradicionais.

Também Petry et al. ${ }^{3}$ destacam a importância da conectividade da planície de inundação central com as áreas remotas de nascentes nos planaltos adjacentes, ressaltando:

Quaisquer alterações nessas conexões, tanto em termos de quantidade como de temporalidade das vazões, resultarão em impactos imprevisíveis aos sistemas de áreas úmidas do Pantanal. Portanto, as áreas de alta e média contribuições bem como os sistemas de cabeceiras que as conectam devem ser priorizadas nos esforços de conservação da bacia. ${ }^{4}$

Dessa a forma, além da fragmentação da matriz do bioma Cerrado na região fisiográfica do Planalto, na bacia, ocorre também a fragmentação dos rios, devido à construção de usinas hidrelétricas, que afeta a conectividade longitudinal desses corpos de água, separando a conexão natural das águas e da biodiversidade aquática, entre as nascentes e a foz.

A pressão para conversão de novas áreas 5 , a sobrepesca, as atividades de drenagem, aterramentos, além da construção de estradas, mineração, ou mesmo o lançamento de poluentes nos corpos hídricos a elas conectados, são fatores que contribuem para a degradação do Pantanal e de outras áreas úmidas em nosso país. ${ }^{6}$

Outro desafio enfrentado pelo Pantanal, que também se repete em outras áreas úmidas na Amazônia brasileira, é a construção de usinas hidrelétricas nos rios formadores do Pantanal. Hoje já estão instaladas na Bacia 8 Usinas Hidrelétricas (UHEs), 7 Centrais de Geração Hidrelétrica (CGHs) e 30 pequenas centrais hidrelétricas (PCHs). Só na porção brasileira, existem 124 novos projetos de empreendimentos energéticos previstos, entre usinas em construção, em licenciamento e em estudos, que correspondiam, em 2010,

3 PETRY, Paulo; RODRIGUES, Sidney et al. Análise de Risco Ecológico da Bacia do Rio Paraguai: Argentina, Bolívia, Brasil e Paraguai. The Nature Conservancy; WWF-Brasil. Brasilia, DF: The Nature Conservancy do Brasil, 2011. p. 20.

4 Idem, p. 24.

5 Dados oficiais (MMA/IBAMA, 2011) indicam que até 2009 o Pantanal havia perdido 2.315 .900 hectares de sua cobertura original, chegando em torno de 15\% no período de 2012-2014. Disponível em: <http://www. wwf.org.br/natureza_brasileira/areas_prioritarias/pantanal/pantanal_pub/?48922/Bacia-do-Alto-Paraguai-Cobertura-Vegetal>

6 Ver a propósito Miranda et al. (2008). Disponível em: http://ainfo.cnptia.embrapa.br/digital/bitstream/ item/105414/1/56722.pdf 
a cerca de $70 \%$ da capacidade de geração de hidroeletricidade da bacia, o que está sendo questionado em ação judicial movida pelo Ministério Público Federal, preocupada com os impactos subdimensionados dessas hidrelétricas no Pantanal..$^{7}$

Atualmente o potencial instalado encontra-se em cerca de 50\% do potencial total, dado o aumento significativo de empreendimentos previstos. Contudo ainda é elevado, considerando a determinação legal (Lei 9.433/1997) de se preservar os usos múltiplos, especialmente a produção pesqueira de importância significativa em termos sociais e econômicos para a bacia, e que requer rios livres de barragens, bem como a determinação constitucional (CF art. $225 \S$ $\left.1^{\circ}, \mathrm{I}\right)$ de se conservar os processos ecológicos essenciais que regem o sistema Bacia do Alto Paraguai/Pantanal, no caso hidro-ecológicos, e prover o manejo ecológico dos seus ecossistemas.

Uma análise DPSIR (Drivers, Presure, Status, Impact, Response) do Guaporé e do Pantanal no Estado de Mato Grosso mostrou que a conversão de ecossistemas para a agricultura e pecuária e as usinas hidrelétricas são as duas principais pressões, oriundas das diretrizes (Drivers) das políticas públicas das décadas de 80, 90 e anos 2000, ainda em curso nessas duas bacias.

O estudo corroborou a argumentação aqui apresentada de que as políticas públicas, iniciativas privadas e da sociedade civil ainda não foram suficientes e são desproporcionais aos impactos causados pelos drivers nos sistemas Guaporé, na Amazônia Meridional e no Pantanal. ${ }^{9}$

O fato é que não se conhece, ainda, o efeito cumulativo e sinérgico dessas Usinas (UHEs, PCHs e CGHs), planejadas e em construção, na dinâmica hidrológica da planície pantaneira, o que torna necessária uma avaliação ambiental integrada desses empreendimentos, de modo a evitar seus impactos cumulativos sobre o pulso sazonal de inundação do Pantanal.

\footnotetext{
7 O Ministério Público, alicerçado em estudos técnicos, alerta que esse conjunto de hidrelétricas pode causar a quebra de conectividade hidrológica de populações e de processos migratórios reprodutivos, afetando a piracema de algumas espécies e também alterar o funcionamento hidrológico do sistema pantaneiro e principalmente a força da carga de nutrientes carregada pelas águas que descem do planalto circundante, fatores que não são amparados pela Política Nacional dos Recursos Hídricos (TRF $2^{\underline{a}}$. Região. Justiça Federal. Seção Judiciária de Campo Grande. Ação Civil Pública. Autos 0000521-24.2012.403.6007).

8 Calheiros et al. 2009. Disponível em: http://ainfo.cnptia.embrapa.br/digital/bitstream/CPAP-2010/57285/1/ DOC102.pdf

9 Conf. DA SILVA, C. J.; SILVA SOUSA, K. N.; IKEDA-CASTRILLON, S. K.; LOPES, C. R. A. S.; DA SILVA NUNES, J. R.; CARNIELLO, M. A.; MARIOTTI, P. R.; LAZARO, W. L.; MORINI, A.; ZAGO, B. W.; FAÇANHA, C. L.; ALBERNAZ-SILVEIRA, R.; LOUREIRO, E.; VIANA, I. G.; OLIVEIRA, R. F.; ALVES DA CRUZ, W. J.; DE ARRUDA, J. C.; SANDER, N. L.; DE FREITAS JUNIOR, D. S.; PINTO, V. R.; DE LIMA, A. C.; JONGMAN, R. T. H. G. Biodiversity and its drivers and pressures of change in the wetlands of the Upper Paraguay-Guapore Ecotone, Mato Grosso (Brazil). Land Use Policy, v. 47, p. 163-178, 2015.
} 
Assim sendo, torna-se imperativo que os órgãos de gestão de recursos hídricos e meio ambiente (federais e estaduais) revejam seus processos de licenciamento e outorga de recursos hídricos adotando, efetivamente, a bacia hidrográfica como unidade de planejamento e gestão, e respeitando os usos múltiplos, como determina a Lei das Águas (Lei 9.433/1997), especialmente até a aprovação do Plano de Bacia da Região Hidrográfica do Paraguai pelo Conselho Nacional de Recursos Hídricos.

Igualmente recomendável a manutenção de rios e trechos de rios ainda sem barramentos para aproveitamento hidrelétrico, visando preservar estes ambientes livres de barragens e, portanto, aptos para a migração reprodutiva de peixes, uma vez que apenas as sub-bacias dos rios Sepotuba, Cabaçal, Alto Paraguai, Mutum, Aricá e Cuiabazinho - em MT, e Piquiri, Coxim, Ariranha, Jauru, Taquari, Negro, Aquidauana, Miranda e Apa - em MS, permanecem atualmente ainda livres de barragens na Bacia do Alto Paraguai, todavia com previsão de sequências de barramentos num mesmo rio, totalizando 124 empreendimentos ainda previstos para geração de energia hidrelétrica. ${ }^{10}$

No caso da Hidrovia Paraguai-Paraná, inserida como uma obra prioritária no PAC 2, esta obra se constitui em potencial ameaça para o Pantanal, já que a intensificação da navegação de grandes barcaças exige um calado mínimo para viabilizar sua utilização comercial. Ou seja, em condições naturais, o Rio Paraguai é navegável por embarcações de grande porte apenas no período das cheias.

Alargar o período em que a navegabilidade é assegurada pressupõe a realização de obras nos canais e a regularização de vazões com impactos de difícil dimensionamento, especialmente no seu Tramo Norte. Por essa razão, justifica-se a restrição à navegação de grande porte no Tramo Norte do Rio Paraguai, entre Cáceres e a foz do Rio Cuiabá, por ser o trecho mais frágil em termos hidrossedimentológicos.

Outros problemas também merecem ser listados pelo potencial de causarem impactos significativos no Pantanal e em outras áreas úmidas, como o avanço da soja na planície pantaneira, a construção de diques e canais de drenagem que alteram a hidrodinâmica natural, a instalação de usinas de álcool, atividades mineradoras e polos siderúrgicos nas áreas de entorno, pesca e turismo predatórios, entre outras atividades e empreendimentos que podem degradar severamente tais ecossistemas.

$\overline{10 \text { Disponível em: }}<$ http://sigel.aneel.gov.br/sigel.html $>$. 
O fato é que esses desafios reclamam a existência de um quadro normativo que considere as peculiaridades das áreas úmidas, sua relevância e fragilidade, estabelecendo mecanismos que possam assegurar sua conservação e uso sustentável.

No ordenamento infraconstitucional, a principal norma geral que disciplinava as áreas úmidas estava contida no Código Florestal (com redação dada pela Lei $\mathrm{n}^{0} 7.803$, de 18/7/1989) que as considerava áreas de preservação permanente, portanto submetidas a um regime jurídico de interesse público com imposição de preservação integral e permanente da flora, vedada sua supressão.

Embora não houvesse, na citada norma, a expressa referência a essas áreas, ela estabelecia a chamada APP ciliar como a faixa marginal ao longo dos curso d'água medida desde o seu nível mais alto, o que abrangia grande parte das áreas úmidas existentes no país (aquelas que ocorrem com a inundação periódica causada pelo transbordamento lateral de rios).

Ocorre que mesmo essa proteção parcial, frequentemente ignorada, foi suprimida com a redação em vigor do art. $4^{\circ}$, I da Lei 12.651/2012, que define a APP ciliar como a faixa marginal ao longo de qualquer curso d'água desde a borda da calba do leito regular, o que exclui dessa proteção as áreas periodicamente alagáveis.

Para "compensar" essa desproteção desses frágeis ecossistemas, o referido Código estabeleceu em seu art. 10 uma regra genérica para "salvaguardar" as áreas úmidas que possam ser consideradas "pantanais e planícies pantaneira" criando uma nova categoria jurídica denominada "Áreas de Uso Restrito".

Contudo, pondera Irigaray: ${ }^{11}$

Obviamente que essa norma, meramente retórica, não tem o alcance necessário e tampouco se presta a assegurar uma proteção efetiva para as áreas úmidas: primeiro porque não existem tais recomendações técnicas; segundo porque não temos sequer uma sistematização de pesquisas que possam embasar a atuação das agências estaduais de meio ambiente; terceiro porque há uma notória pressão no parlamento brasileiro para reduzir as áreas protegidas e flexibilizar ainda mais a legislação ambiental brasileira.

11 IRIGARAY, Carlos Teodoro J. H. Áreas Úmidas Especialmente "Des” Protegidas no Direito Brasileiro: O Caso do Pantanal Mato-grossense e os Desafios e Perspectivas para sua Conservação. Revista de Estudos Sociais v. 17 n. 34, 2015. Cuiabá: Faculdade de Economia. Disponível em: http://periodicoscientificos.ufmt.br/ojs/ index.php/res/article/view/2602 
Por outro lado, não se pode ignorar a relevância de um marco regulatório, como base para a atuação estatal e também para articulação da sociedade civil na luta pela observância das normas criadas, razão pela qual merece apoio a iniciativa que visa dotar o Pantanal de uma legislação que assegure sua conservação.

Um passo importante foi dado com a propositura do Projeto de Lei do Senado (PLS) 750/2011 que dispõe sobre a gestão e proteção do bioma Pantanal, cabendo à comunidade cientifica e à sociedade oferecerem sua contribuição para o seu aprimoramento.

Sem prejuízo das medidas que constam do citado PLS destaca-se a necessidade de um sistema que possa coordenar as ações de gestão dessa importante área úmida. Com esse objetivo a criação de um Conselho Gestor do Pantanal acredita-se relevante para permitir integração das ações do poder público (federal e estaduais) na conservação do Pantanal Mato-grossense.

Além disso, considerando a necessidade da definir legalmente as instituições oficiais de pesquisa que deverão oferecer as recomendações técnicas para a exploração ecologicamente sustentável do Pantanal (art. 10 do Código Florestal), e contribuir para a definição da delimitação do Pantanal Mato-grossense, propõe-se uma definição dessas instituições e da estratégia para consultas e oferecimento de recomendações, para o desempenho dessa atividade, sem impedir que essa regulamentação se faça previamente por meio de Resolução do Conama, tendo em vista o risco de morosidade na tramitação do citado projeto de lei.

Assim, é recomendável que se dê substância ao conceito de áreas de uso restrito, indicando quais os macrohabitats que assim devem ser considerados e quais as restrições de uso que devem estar previamente definidas, bem como os incentivos que devem ser dados às propriedades que possam ser reconhecidas como Fazendas Pantaneiras Sustentáveis ${ }^{12}{ }^{13}$ para futura certificação.

Da mesma forma, uma especial atenção deve ser dada à proteção dos ambientes aquáticos, regulamentando aspectos da navegação, da construção de hidrelétricas e outros usos que possam comprometer o pulso de inundação e a dinâmica hidrológica do Pantanal.

12 AMANCIO, C. O. da G.; ARAUJO, M. T. B. D.; SANTOS, S. A.; NARCISO, M. G.; OlIVEIRA, M. D. Protocolo: Índice de Bem-Estar Social (IBS) para a Fazenda Pantaneira Sustentável (FPS). Disponível em: https:// www.embrapa.br/pantanal/busca-de-publicacoes/-/publicacao/1054996/protocolo-indice-de-bem-estar-social-ibs-para-a-fazenda-pantaneira-sustentavel-fps. Acesso em: 1 nov. 2017.

13 SANTOS, S. A. et al., 2017. A fuzzy logic-based tool to assess beef cattle ranching sustainability in complex environmental systems. Journal of Environmental Management, v. 198, p. 95-106. 
Igualmente relevante é a previsão de normas que disponham sobre o emprego de instrumentos econômicos na gestão do Pantanal, considerando que as normas de comando e controle mostram-se insuficientes para garantir a conservação desse importante patrimônio nacional.

Pondera-se que, a despeito da relevância do Pantanal Mato-grossense, poucas foram as iniciativas legislativas visando a sua proteção na esfera federal, destacando-se, mais recentemente o Projeto de Lei $n^{\circ} 3.503$, de 1997 (Senado Federal - PLS n ${ }^{80 / 96)}$, de autoria do então senador Júlio Campos (MT) e o Projeto de Lei $\mathrm{n}^{\circ}$ 750, de 2011 (Senado Federal) de autoria do então senador Blairo Maggi (MT).

No Projeto de Pesquisa Pantanal Legal, constatada a existência de um vazio legal e a insuficiência da proteção do Pantanal enquanto "área de uso restrito", tomou-se como ponto de partida o PLS $\mathrm{n}^{\circ} 750$, por ser mais recente e mais abrangente, visando avançar na construção de um substitutivo que possa ser aprimorado e levado à discussão no Congresso Nacional.

O texto abaixo representa a versão atual da minuta em discussão, objeto de workshops e consultas públicas realizadas nos anos de 2016/2017, ressaltando que o Grupo de Pesquisa segue trabalhando visando ao seu aprimoramento, portanto aberto às contribuições que visem enriquecê-lo.

\section{Proposta de Substitutivo ao Projeto de Lei do Senado no 750, de 2011}

Dispõe sobre a Política de Gestão e Proteção do Pantanal Mato-grossense. O CONGRESSO NACIONAL decreta:

\section{CAPÍTULO I DAS DISPOSIÇÕES GERAIS}

Art. $1^{\circ}$ Esta Lei estabelece a Política de Gestão e Proteção do Pantanal Mato-grossense, define seus princípios e as atribuições do poder público para a manutenção de sua sustentabilidade ambiental, econômica e social.

$\mathbb{S 1}^{\circ}$ O Pantanal, reconhecido constitucionalmente como patrimônio nacional, é uma área úmida que pertence a categoria de planície alagável, localizada na Bacia do Alto Rio Paraguai, constituída principalmente por savanas alagáveis anualmente.

$\mathbb{\$} \mathbf{2}^{\circ}$ A proteção prevista nesta lei abrange a planície pantaneira e também os rios que para ela drenam.

Art. $2^{\circ}$ Para os efeitos dessa Lei, entende-se por: 
I - aquicultor: a pessoa física ou jurídica que, registrada e licenciada pelas autoridades competentes, exerce a aquicultura com fins comerciais;

II - aquicultura: a atividade de cultivo de organismos cujo ciclo de vida em condições naturais se dá total ou parcialmente em meio aquático, implicando a propriedade do estoque sob cultivo, equiparada à atividade agropecuária;

III - arbustais inundáveis: áreas densamente cobertas por arbustos em áreas de influência da inundação fluvial, nos quais pode haver ou não predominância de uma espécie característica, tais como bamburro, pombeirais e espinheirais;

IV - arbustais de savana: ocorrem em áreas savânicas abertas, sazonalmente inundáveis, dominadas por gramíneas com presença de arbustos;

V - aterro: áreas com níveis elevados por deposição de solo ou outros materiais, efetuadas pelas comunidades tradicionais e populações indígenas para a construção de casas ou a plantação de lavoura de subsistência;

VI - atividades econômicas sustentáveis: atividades que promovem a inclusão social, o bem-estar econômico e a conservação dos bens ambientais;

VII- baía: corpo d'água perene ou temporário, isolado ou conectado a um curso d'água, com vegetação terrestre nas bordas ou eventualmente flutuante;

VIII - brejo: área inundada, coberta por vegetação natural própria, com predominância de arbustos, trepadeiras e herbáceas, caracterizada pela presença de vegetação hidrófila, que pode secar em anos excepcionais;

IX - campos limpos de média e alta inundação: São os campos de mimoso, mimosinho, mimoso de talo e arrozais, reconhecidos por alta qualidade nutricional. Caracteriza-se por apresentar uma fase aquática com dominância de plantas aquáticas e outra terrestre no período da seca com abundância de gramíneas;

X - campos limpos savânicos: Áreas cobertas com gramíneas e outras plantas herbáceas formando touceiras (macegas), com inundação rasa ou pouco encharcado. Nessas áreas as gramíneas são mais "duras" (lignificadas) e de baixa aceitabilidade pelo gado e animais silvestres, sendo frequente o uso do fogo para promover o rebrote das forrageiras;

XI - capões de mato: elevações do terreno de forma circular ou elíptica, onde cresce vegetação arbórea, normalmente rodeadas por campos associados à inundação ou ao encharcamento sazonal dos solos;

XII - cordilheira: elevações que apresentam formas sinuosas, alongadas e extensas, de origem relacionada à deposição aluvial, com predominância de vegetação arbórea, normalmente rodeadas por campos associados à inundação ou ao encharcamento sazonal dos solos; 
XIII - corixo: curso d'água natural permanente, intermitente ou efêmero, com fluxo que se alterna em função da sazonalidade climática e do ciclo hidrológico, que interliga baías, lagoas, córregos e rios na planície alagável, com função hídrica de enchê-la e esvaziá-la, e função ecológica essencial como, por exemplo, servir de repositório de biota para colonização dos macrohabitats aquáticos;

XIV - defeso: a paralisação temporária da pesca para a preservação da espécie, tendo como motivação a reprodução e/ou o recrutamento, bem como as paralisações causadas por fenômenos naturais ou acidentes;

$\mathrm{XV}$ - dique artificial: aterro levantado com objetivo de impedir ou controlar a entrada e saída de água;

XVI - diques marginais naturais: porção de terra mais elevada na margem dos rios, córregos e corixos, proveniente do transporte pelas águas durante as cheias do material em suspensão que ali se deposita, de pequena extensão, com altura decrescente no sentido transversal ao curso d'água, ocupado ao longo do tempo pela comunidade pantaneira e por ribeirinhos, fazendeiros e pousadas;

XVII - fazenda pantaneira sustentável - FPS: imóvel rural localizado na planície pantaneira onde sejam adotadas práticas conservacionistas, admitido o uso sustentável dos recursos naturais e o exercício de atividades econômicas tais como, o ecoturismo e a pecuária extensiva, com respeito às fitofisionomias, aos macrohabitats e à conservação dos processos hidro-ecológicos que regem o ecossistema Pantanal. Os requisitos para qualificação de uma propriedade rural como fazenda pantaneira sustentável e sua certificação serão definidos na forma do regulamento, ouvidos os órgãos oficiais de pesquisa;

XVIII - fazendeiros tradicionais: aqueles que praticam o uso sábio, realizando uma pecuária extensiva, mantendo a diversidade dos macrohabitats e valores não comerciais pelo tipo de manejo que praticam;

XIX - florestas inundáveis: também considerados como diques marginais atuais, são terraços aluviais que podem apresentar diferentes graus de inundação, cobertos por cerrados florestados e outros tipos de florestas;

XX - macrohabitats: área espacial sujeitas a condições hidrológicas similares e com uma vegetação superior característica, na qual os indivíduos desenvolvem todas as suas funções biológicas;

XXI - meandros de rio: trecho da calha do rio, com duas curvaturas consecutivas e alternadas, fruto da interação entre as vazões líquidas e sólidas impostas e a erosividade de suas margens e que, nos leitos aluvionares, pode apresentar sequência de curvas separadas por trechos retilíneos curtos; 
XXII - murundum: microrrelevo em forma de pequenas elevações ou montículos ou cocurutos, geralmente arredondados, com altura entre dez e cento e cinquenta centímetros e diâmetro de até vinte metros, temporariamente inundável nas partes mais baixas durante o período chuvoso, formado em solos hidromórficos com deficiência em drenagem, que contém, comumente, no perfil, concreções ferruginosas e é de grande importância ecológica por controlar o fluxo de água, a deposição de nutrientes, a conservação de água de superfície e a biodiversidade;

XXIII - pesca de subsistência: toda operação, ação ou ato tendente a extrair, colher, apanhar, apreender ou capturar recursos pesqueiros praticada de forma artesanal por populações ribeirinhas, tradicionais ou pantaneiras, sem fins comerciais, para complementação da alimentação familiar, inclusive do pescador profissional artesanal no período da piracema;

XXIV - pulso de inundação: inundação sazonal característica das bacias hidrográficas do Pantanal, com os níveis de enchente, cheia, vazante e seca influenciando a produtividade e a diversidade vegetal e animal da região;

XXV - sustentabilidade ambiental: manutenção da capacidade de sustentação dos ecossistemas, o que implica a capacidade de absorção e recomposição dos ecossistemas em face das interferências antrópicas;

XXVI - uso sábio: aquele praticado por populações tradicionais na conservação e manutenção do ecossistema;

XXVII - vazante: área rebaixada em relação aos terrenos contíguos ou planície, levemente inclinada, periodicamente inundada pelo refluxo lateral de rios e lagos ou pela precipitação direta, contribuindo para a drenagem das águas sazonais;

XXVIII - vereda: fitofisionomia de savana, encontrada em solos hidromórficos, usualmente com palmáceas, sem formar dossel, em meio a agrupamentos de espécies arbustivo-herbáceas.

Art. ${ }^{\circ}$ A Política de Gestão e Proteção do Pantanal tem por objetivo promover a preservação e a conservação dos bens ambientais, a melhoria e a recuperação da qualidade ambiental, bem como assegurar a manutenção da sustentabilidade e o bem-estar da população envolvida, atendidos os seguintes princípios:

I - da precaução;

II - do poluidor-pagador;

III - do usuário-pagador;

IV - do conservador-recebedor;

V - da prevenção; 
VI - da participação social e da descentralização;

VII - do desenvolvimento sustentável;

VIII - do respeito às formas de uso e de gestão dos bens ambientais utilizados por povos e comunidades tradicionais, bem como a sua valorização;

IX - do respeito à diversidade biológica e aos valores ecológicos, genéticos, sociais, econômicos, cientificos, educacionais, culturais, religiosos, recreativos e estéticos associados.

Art. $4^{\circ}$ São diretrizes da Política de Gestão e Proteção do Pantanal:

I - a articulação dos órgãos federais, estaduais e municipais de meio ambiente, desenvolvimento rural, indústria, comércio, turismo e gestão de recursos hídricos e desses órgãos com a sociedade civil organizada;

II - a integração das gestões ambiental, dos recursos hídricos e do uso do solo;

III - a promoção dos meios necessários para a efetiva participação dos povos e comunidades tradicionais nas instâncias de controle social e nos processos decisórios relacionados aos seus direitos e interesses;

IV - a garantia dos direitos individuais e coletivos concernentes aos povos e comunidades tradicionais à autodeterminação na construção de políticas de gestão em território tradicional;

V - a consolidação e a ampliação de parcerias internacional, nacional, estadual, interestadual e setorial para o intercâmbio de informações e a integração de políticas públicas articuladas e aplicáveis ao Pantanal;

VI - a ordenação da ocupação territorial do Pantanal, na forma da lei;

VII - o estímulo e o apoio às atividades econômicas sustentáveis de acordo com a natureza do ecossistema de áreas úmidas;

VIII - o reconhecimento, a implementação e o subsídio a atividades sustentáveis desenvolvidas por povos e comunidades tradicionais;

IX - o incentivo a ações que se coadunam com os objetivos da Convenção-Quadro de Mudanças Climáticas e seus Protocolos, da Convenção sobre Diversidade Biológica, Metas de AICHI e Convenção RAMSAR e o estabelecimento de restrições para as ações contrárias aos objetivos da Convenção;

$\mathrm{X}$ - o incentivo a atividades de ecoturismo como forma de gerar emprego e renda e de fiscalizar, proteger e divulgar o ambiente pantaneiro.

Art. $5^{\circ}$ A proteção e a utilização dos recursos naturais no Pantanal far-se-ão dentro de condições que assegurem:

I - a manutenção e a recuperação da biodiversidade, vegetação, fauna e regime hídrico do Pantanal para as presentes e futuras gerações; 
II - o estímulo à pesquisa, à difusão de tecnologias de manejo sustentável da vegetação e à formação de uma consciência pública sobre a necessidade de recuperação e manutenção dos ecossistemas;

III - o fomento de atividades públicas e privadas compatíveis com a manutenção do equilibrio ecológico;

IV - o disciplinamento da ocupação rural e urbana, de forma a harmonizar o crescimento econômico com a manutenção do equilibrio ecológico.

Art. $6^{\circ}$ Incumbe ao poder público:

I - articular a criação de uma política integrada para Pantanal;

II - fomentar a certificação ambiental das atividades sustentáveis desenvolvidas no Pantanal;

III - incentivar a recuperação de áreas degradadas;

IV - promover o ordenamento do turismo no Pantanal, em especial do ecoturismo, em conjunto com ações de educação ambiental;

V - criar e implementar mecanismos de prevenção e combate à biopirataria e ao tráfico de animais silvestres;

VI - promover a criação de mecanismos econômicos de incentivo às atividades de preservação e conservação ambiental;

VII - incentivar ações que contribuam para o manejo sustentável dos recursos pesqueiros, da fauna silvestre e dos macrohabitats de campos nativos típica do Pantanal, mediante plano de manejo;

VIII - promover pesquisas cientificas, sociais e econômicas visando à implementação de novas unidades de conservação da natureza e de corredores ecológicos no Pantanal;

IX - incentivar as ações de manutenção dos estoques pesqueiros, agregando valor ao pescado capturado pela pesca de subsistência, mediante o desenvolvimento das cadeias produtivas da carne e do couro do peixe, e pelos pescadores amadores, mediante o incentivo ao ecoturismo;

$\mathrm{X}$ - estimular formas ambientalmente corretas de produção agropecuária, manejo florestal, agroextrativismo, silvicultura e geração de energia no Pantanal;

XI - promover ações com a finalidade de implantar os serviços públicos de saneamento básico nas bacias hidrográficas do Pantanal, conforme o estabelecido na Lei $n^{\circ} 11.445$, de 5 de janeiro de 2007, com especial atenção à implantação de estações de tratamento de esgoto;

XII - a coleta e a disposição final adequada dos resíduos sólidos, conforme o estabelecido pela Lei $\mathrm{n}^{\circ} 12.305$, de 2 de agosto de 2010; 
XIII - incentivar a manutenção e a conservação de áreas naturais, mediante incentivo à criação de unidades de conservação da natureza no Pantanal;

XIV - desenvolver programas de monitoramento da fauna, da flora, qualidade da água e de controle de espécies exóticas no Pantanal;

$\mathrm{XV}$ - realizar diagnóstico e monitoramento dos impactos ambientais no Pantanal e propor programas que visem à minimização desses impactos, com a participação das empresas, comunidade cientifica e dos produtores rurais, de modo a contribuir para a melhoria da gestão ambiental e permitir o aperfeiçoamento de acompanhamento e controle;

XVI - implantar sistema de monitoramento, controle e fiscalização da pesca, em todas as suas modalidades, mediante o fomento de estudos estatísticos quantitativos e qualitativos que abranjam o estoque e a produção das áreas naturais utilizadas para essa atividade;

XVII - fomentar ações visando ao manejo sustentável dos recursos vegetais nativos e de macrohabitats;

XVIII - controlar e fiscalizar a extração, o transporte e o comércio de iscas vivas;

XIX - ordenar as atividades poluidoras ou degradadoras do meio ambiente, implantadas e a serem implantadas no Pantanal.

\section{CAPÍTULO II \\ DÓS ÓRGÃOS E INSTITUIÇÕES DE APOIO À GESTÃo}

\section{Seção I \\ Do Conselho Gestor}

Art. $7^{\circ}$ Fica criado o Conselho Gestor do Pantanal - CG-Pantanal, com as atribuições de promover a gestão integrada e participativa do Pantanal, composto por representantes dos seguintes órgãos e instituições:

I - Ministério do Meio Ambiente, Recursos Hídricos e Amazônia Legal - MMA;

II - Instituto Brasileiro de Meio Ambiente e Recursos Naturais Renováveis - IBAMA;

III - Instituto Chico Mendes de Biodiversidade - ICMBio;

IV - Secretaria de Estado do Meio Ambiente de Mato Grosso;

V - Secretaria de Estado do Meio Ambiente de Mato Grosso do Sul.

Parágrafo único. O Conselho Gestor poderá convidar representantes de entidades ambientalistas, das instituições de Ensino e Pesquisa e de organizações representativas das populações tradicionais, do setor agropecuário, de extração mineral, da navegação e da indústria, bem como membros do Con- 
selho da Reserva da Biosfera do Pantanal e do Comitê de Bacia Hidrográfica do Alto Paraguai, sempre que os temas em apreciação disserem respeito ao âmbito de atuação dessas entidades.

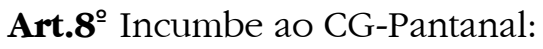

I - Aprovar o Plano de Gestão do Pantanal a ser elaborado conjuntamente pelos órgãos de meio ambiente dos Estados de Mato Grosso e Mato Grosso do Sul, com observância às diretrizes estabelecidas no art. $4^{\circ}$ desta Lei;

II - promover o debate das iniciativas legislativas e políticas públicas que tenham impactos sobre os ecossistemas pantaneiros e articular a atuação das entidades intervenientes;

III - acompanhar a execução do Plano de Gestão do Pantanal e sugerir as providências necessárias ao cumprimento de suas metas;

IV - definir os usos ecologicamente sustentáveis com observância aos diferentes macrohabitats do bioma Pantanal indicando, quando for o caso e sem prejuízo do disposto nesta lei, restrições ao funcionamento de determinadas atividades;

V - indicar áreas prioritárias para a criação de unidades de conservação, compensações e pagamento por serviços ambientais.

\section{Seção II}

\section{Das Instituições de Pesquisa}

Art.9 ${ }^{\circ}$ Para fins de apoio técnico-cientifico à conservação e uso sustentável do Pantanal, são consideradas como instituições oficiais de pesquisa:

I - Instituto Nacional de Pesquisa do Pantanal - INPP;

II - Universidades federais e estaduais de Mato Grosso e Mato Grosso do Sul; III - Empresa Brasileira de Pesquisa Agropecuária - EMBRAPA Pantanal.

$\$ \mathbf{\$ 1}$ Sempre que considere necessário os órgãos ambientais formularão consulta às instituições previstas no caput deste artigo, sem prejuízo de recomendações que estas possam oferecer espontaneamente.

$\$ \mathbf{2}^{\mathbf{0}}$ As recomendações das instituições oficiais de pesquisa deverão serão publicadas e observadas pelos órgão estaduais de meio ambiente em suas políticas e procedimentos que envolvam a proteção do Pantanal.

$\$ 3^{\mathbf{o}}$ A definição de usos ecologicamente sustentáveis pelos órgãos oficiais de pesquisa deve observar os diferentes macrohabitats do bioma pantanal podendo indicar, quando for o caso e sem prejuízo do disposto nesta lei, restrições ao funcionamento de determinadas atividades. 


\section{CAPÍTULO III \\ DAS ÁREAS PROTEGIDAS}

\section{Seção I}

\section{Das Áreas de Preservação Permanente}

Art.10 Aplica-se ao disciplinamento das Áreas de Preservação Permanente no Pantanal, as normas previstas na Lei 12.651, de 2.012 (Código Florestal), com os seguintes acréscimos:

I - a supressão da vegetação nativa nas Áreas de Preservação Permanente deverá ser realizada por meio de prévio licenciamento junto aos órgãos ambientais competentes.

II - nas Áreas de Preservação Permanente será permitida a construção de estradas para acesso às propriedades rurais, desde que não impeçam o fluxo de água.

III - é admitido, para a pequena propriedade ou posse rural familiar na planície pantaneira, o plantio de culturas temporárias e sazonais de vazante de ciclo curto, na faixa de terra que fica exposta no período de vazante dos rios ou lagos, desde que não implique supressão de novas áreas de vegetação nativa, seja conservada a qualidade da água e do solo e seja protegida a fauna silvestre.

Art.11 A intervenção ou a supressão de vegetação nativa em Área de Preservação Permanente no Pantanal somente ocorrerá nas hipóteses de utilidade pública, de interesse social ou de baixo impacto ambiental previstas nesta Lei.

Parágrafo único. Considera-se de interesse social, na planície pantaneira as instalações destinadas à habitação dos ribeirinhos, sede e retiros de fazendas e desenvolvimento de atividades turísticas, que poderão ser autorizadas pelo órgão ambiental, vedadas qualquer intervenção que impeçam o fluxo da água.

Art.12 Nos imóveis rurais com até 4 (quatro) módulos fiscais, é admitida, nas áreas de que tratam os incisos I e II do artigo 10, a prática da aquicultura e a infraestrutura física diretamente a ela associada, desde que:

I - sejam adotadas práticas sustentáveis de manejo de solo e água e de recursos hídricos, garantindo sua qualidade e quantidade;

II - esteja de acordo com os respectivos planos de bacia ou planos de gestão de recursos hídricos;

III - seja realizado o licenciamento pelo órgão ambiental competente;

IV - não implique novas supressões de vegetação nativa;

$\mathrm{V}$ - o imóvel esteja inserido num projeto de licenciamento ambiental de propriedades rurais. 


\section{Seção II \\ Das Áreas de Reserva Legal}

Art.13 O art. 12 da Lei n 12.651, de 25 de maio de 2012, passa a vigorar com os seguintes acréscimos:

Art. 12.

I -

II - Localizado no Pantanal Mato-Grossense: 50\% (cinquenta por cento) no imóvel situado em área de cerrado ou outras formas de vegetação;

III - localizado nas demais regiões do País: 20\% (vinte por cento).

$\$ \mathbf{1}^{\circ}$ Para a quantificação do percentual de reserva legal a classificação da fitofisionomia vegetal será feita pelo órgão ambiental considerando o mapa do Probio GEFF Pantanal ou outro estudo oficial capaz de defini-la com maior precisão.

$\$ \mathbf{2}^{\circ}$ Havendo dúvida quanto à classificação da fitofisionomia vegetal, o responsável técnico deverá apresentar relatório/laudo técnico de identificação de tipologia vegetal, sendo indispensável a vistoria técnica, realizada pelo órgão ambiental, às expensas do interessado.

Art.14 Os proprietários ou possuidores de imóveis rurais que realizaram supressão de vegetação nativa respeitando os percentuais de Reserva Legal previstos pela legislação em vigor à época em que ocorreu a supressão são dispensados de promover a recomposição, compensação ou regeneração para os percentuais exigidos nesta Lei.

Art.15 Em caso de fracionamento do imóvel rural, a qualquer título, será considerada, para fins do disposto no caput do art. 13, a área do imóvel antes do fracionamento.

\section{Seção III \\ Das Áreas de uso restrito}

Art.16 Nos pantanais e planícies pantaneiras, é permitida a exploração ecologicamente sustentável, devendo-se considerar as recomendações técnicas dos órgãos oficiais de pesquisa, ficando novas supressões de vegetação nativa para uso alternativo do solo condicionadas à autorização do órgão estadual do meio ambiente.

Art.17 Sem prejuízo das recomendações técnicas dos órgãos oficiais de pesquisa, serão objeto de especial proteção, nos termos desta Lei, os seguintes macrohabitats:

I - cordilheiras;

II - corixos;

III - meandros de rios; 
IV - baías e lagoas marginais;

$\mathrm{V}$ - vazantes;

VI - diques marginais naturais;

VII - capões de mato e os murunduns;

VIII - arbustais inundáveis;

IX - arbustais de savana;

$\mathrm{X}$ - florestas inundáveis;

XI - campos limpos de média e alta inundação;

XII - campos limpos savânicos;

XIII - brejos;

XIV - ilhas fluviais.

$\$ \mathbf{1 1}^{\circ}$. Nas áreas de uso restrito previstas neste artigo é vedado o emprego de agrotóxico, o plantio de transgênicos e a abertura de canais de drenagem.

$\$ \mathbf{2}^{\circ}$. Nos capões de mato, murundus, cordilheiras e diques marginais naturais é vedado o desmatamento, exceto quando for para acesso habitação dos ribeirinhos, sede e retiros de fazendas e desenvolvimento de atividades turísticas, vedadas às intervenções que impeçam o fluxo da água.

$\mathbf{S 3}^{\circ}$. São vedados nas cordilheiras e terras altas do Pantanal o corte-raso, permitido o manejo florestal previamente autorizado pelo órgão ambiental.

$\$ 4^{\circ}$. Nos arbustais inundáveis serão admitidas a pecuária extensiva, o turismo ecológico, o manejo sustentável desde que assegurada a manutenção do macrohabitat original.

$\$ 5^{\circ}$. Nos campos limpos savânicos, será permitida a pecuária extensiva com manejo sustentável. A substituição de gramíneas e o desenvolvimento de modelos de manejo adaptativo que envolva o uso de espécies exóticas, poderão ser autorizadas desde que observadas as recomendações das instituições oficiais de pesquisa.

$\$ 6^{\circ}$. Nas áreas de vazantes e nos campos limpos de média e alta inundação somente será permitida a pecuária extensiva, sendo obrigatório manejo para a manutenção do macrohabitat original, vedada qualquer tipo de substituição de pastagem.

Art.16 Nas áreas com restrição de uso relacionadas neste artigo poderão ser autorizadas pelo órgão estadual de meio ambiente:

I - a construção de estradas para acesso as propriedades rurais e hotéis, desde que não impeçam o fluxo de água;

II - a substituição de gramíneas e o desenvolvimento de modelos de manejo adaptativo que envolva o uso de espécies exóticas, hipótese em que deverão ser observadas as recomendações das instituições oficiais de pesquisa; 
III - a restauração de campos nativos, nas áreas de arbustais com predominância de espécies invasoras, tais como os canjiquerais (Byrsonima orbignyana), o pombeiro (Combretum laxum) e nas florestadas por cambará (Vochysia divergens), hipótese em que deverão ser observadas as recomendações das instituições oficiais de pesquisa e considerados os estágios sucessionais com condições de possíveis restauros.

Parágrafo único. A substituição de pastagem não será permitida nas áreas de vazantes e nos campos limpos de média e alta inundação, admitindo-se apenas a pecuária extensiva, sendo obrigatório o manejo para a manutenção do macrohabitat original.

Art.18 Ressalvadas as restrições previstas para os macrohabitats relacionados nesta lei, a intervenção ou a supressão de vegetação nativa nas áreas com restrição de uso somente poderá ser realizada por meio de prévio licenciamento junto às organizações estaduais de meio ambiente na forma do regulamento.

Art.19 Os órgãos ambientais, atendendo recomendação dos órgãos oficiais de pesquisa, definirão uma zona de amortecimento para a planície inundável do Pantanal, estabelecendo sua delimitação e as restrições de uso.

\section{CAPÍTULO IV \\ DA PROTEÇÃo dOS AMBIENTES AQUÁTICOS}

Art.20 A navegação comercial nos rios formadores do Pantanal deve ser compatibilizada com a conservação e preservação do meio ambiente, buscando a manutenção da diversidade biológica e recursos hídricos, adaptando-se as embarcações aos rios, vedado o transporte de produtos potencialmente perigosos.

Parágrafo único. Na bacia hidrográfica do Alto Paraguai estão vedadas as intervenções irreversíveis nos cursos d'água que alterem a velocidade do escoamento, o volume de água e a capacidade do transporte de sedimentos.

Art.21 Para a construção de hidrelétricas nos rios formadores do Pantanal é obrigatório o atendimento ao plano de gestão de recursos hídricos da bacia, visando reduzir os efeitos sobre o pulso de inundação em todo o sistema.

Parágrafo único. Nas hidrelétricas com reservatórios de grande porte construídas nos rios que integram a Bacia do Alto Paraguai a liberação de água deverá observar o pulso de inundação do Pantanal e as recomendações dos órgãos oficiais de pesquisa, de acordo com o hidrograma sazonal.

Art.22 No uso e construção de estradas no Pantanal deverá ser observada a dinâmica hidrológica, visando à minimização dos impactos de represamento. 
Parágrafo único. As estradas que, de alguma forma interferirem no fluxo das águas, deverão ser construídas com pontes, manilhas e outros mecanismos que possibilitem o fluxo das águas.

\section{CAPÍTULO V \\ DAS RESTRIÇÕES GERAIS DE USO}

Art.23 Ficam vedados, no Pantanal:

I - o licenciamento de criatórios de espécies da fauna que não sejam autóctones da bacia hidrográfica;

II - o plantio de transgênicos, salvo em cultivos de subsistência;

III - a construção de diques, barragens ou obras de alterações dos cursos d'água e corpos d'água perenes ou intermitentes, tais como canais de rios, lagos e áreas periodicamente alagáveis. Esta vedação não se aplica à construção de açudes e tanques para piscicultura e pecuária extensiva, estabelecidos fora das linhas de drenagens, ou quando destinados à recuperação ambiental;

IV - a instalação e funcionamento de atividades de médio e alto grau de poluição e/ou degradação ambiental no Pantanal, tais como: plantio de cana, implantação de usinas de álcool e açúcar e carvoarias.

Art.24 Qualquer empreendimento ou atividade localizado no Pantanal deverá, obrigatoriamente, ser previamente vistoriado pelo órgão ambiental competente antes da emissão de parecer técnico conclusivo do processo de licenciamento.

Art.25 As atividades de piscicultura e criação de animais da fauna silvestre só poderão ser licenciadas se as espécies forem de ocorrência natural no Pantanal.

Art.26 O poder público implementará ações com o objetivo de conciliar o equilibrio entre o princípio da sustentabilidade dos recursos pesqueiros e a obtenção de melhores resultados econômicos e sociais por parte dos pescadores amadores e profissionais, calculando, autorizando ou estabelecendo, em cada caso:

I - os regimes de acesso;

II - a captura total permissível;

III - o esforço de pesca sustentável;

IV - os períodos de defeso;

$\mathrm{V}$ - as temporadas de pesca;

VI - os tamanhos de captura;

VII - as áreas interditadas ou de reservas;

VIII - as artes, os aparelhos, os métodos e os sistemas de pesca e cultivo; 
IX - a capacidade de suporte dos ambientes;

$\mathrm{X}$ - as necessárias ações de monitoramento, controle e fiscalização da atividade;

XI - a proteção de indivíduos em processo de reprodução ou recomposição de estoques.

Art.27 Os órgãos ambientais competentes deverão identificar as barragens, diques e aterros existentes no Pantanal, fixando, aos responsáveis, pessoas físicas ou jurídicas, públicas ou privadas, prazo para remoção ou adequação, se ficar constatado que causam significativos danos ao ecossistema do Pantanal.

Art.28 A limpeza de pastagens e recuperação das áreas degradas deverão ser feitas mediante prévia autorização do órgão ambiental, observadas as recomendações dos órgãos oficiais de pesquisa.

\section{CAPÍtULLO VI \\ DOS INSTRUMENTOS ECONÔMICOS}

Art.29 O poder público regulamentará os mecanismos de pagamento por serviços ambientais, compensação e incentivos fiscais visando fomentar a sustentabilidade socioeconômica e ambiental do Pantanal Mato-grossense, especialmente a conservação do planalto circundante e planície localizados na Bacia do Alto Paraguai e a criação de Reservas Particulares de Patrimônio Natural.

$\$ \mathbf{1}^{\circ} \mathrm{Na}$ regulamentação dos incentivos econômicos ambientais, será priorizado o atendimento a fazendeiros tradicionais e observadas as seguintes características da área beneficiada:

I - a importância e representatividade ambientais do ecossistema e da área rural;

II - o valor paisagístico, estético e turístico;

III - o respeito às obrigações impostas pela legislação ambiental;

$\$ \mathbf{2}^{\circ}$ Os incentivos de que trata este Capítulo não excluem ou restringem outros benefícios, abatimentos e deduções em vigor, em especial as doações a entidades de utilidade pública efetuadas por pessoas físicas ou jurídicas.

Art. 30 Como incentivo à regularização e ampliação de áreas protegidas no Pantanal, e, considerando a predominância do cerrado na planície pantaneira, ficam autorizadas compensações de reserva legal do cerrado no Pantanal Mato-grossense.

$\int \mathbf{1}^{\mathbf{0}}$ Os imóveis rurais certificadas como Fazenda Pantaneira Sustentável - FPS por certificadoras independentes conveniadas aos órgãos estaduais do 
meio ambiente poderão ter sua área total utilizada para fins de compensação ambiental, sem prejuízo da continuidade do uso econômico sustentável.

\ 20 Verificada a superveniente inobservância dos requisitos exigidos para configuração do imóvel como Fazenda Pantaneira Sustentável, o mesmo perderá a sua certificação, com o consequente cancelamento das compensações autorizadas.

\section{CAPÍTULO VII \\ DAS PENALIDADES}

Art. 31 A ação ou omissão das pessoas físicas ou jurídicas que importem inobservância aos preceitos desta Lei e a seus regulamentos ou resultem em dano à flora, à fauna e aos demais atributos naturais do Pantanal sujeitam os infratores às sanções previstas em lei, em especial as dispostas na Lei n ${ }^{\circ} \mathbf{9 . 6 0 5}$, de 12 de fevereiro de 1998, e seus decretos regulamentadores.

\section{CAPÍtULO VIII DAS DISPOSIÇÕES FINAIS}

Art. 32 Os órgãos ambientais competentes promoverão a realização de plano de manejo para as Unidades de Conservação existentes no Pantanal, no prazo de até três anos a contar da publicação desta Lei.

Art. 33 As delimitações do Pantanal Mato-grossense serão definidas pelos órgãos oficiais de pesquisa. Enquanto não concluídos os estudos necessários a essa definição, observar-se-á a delimitação definida pelo RADAM BRASIL, ou leis estaduais, sem prejuízo da realização de vistorias para confirmação da fitofisionomia vegetal.

Art. 34 Não haverá, em qualquer hipótese, direito à regularização de futuras intervenções ou supressões de vegetação nativa, além dos previstos nesta Lei.

Art. 35 Esta lei entra em vigor na data de sua publicação.

\section{Considerações finais}

Na missão de garantir a incolumidade das áreas úmidas, a proteção jurídica desses ecossistemas deve avançar, não apenas como forma de preservar um patrimônio ecológico, como também de assegurar sua utilização sustentável, isso implica valorizar o uso sábio dos pantaneiros e das populações tradicionais que garantiram durante os últimos séculos a conservação desse patrimônio nacional. 
Todavia, como assinalado, inúmeras são as ameaças e desafios para a conservação das áreas úmidas no Brasil. Alguns desses desafios poderiam ser enfrentados com a legislação ambiental já existente no país, contudo, as peculiaridades do Pantanal reclamam uma proteção diferenciada, compatível com a sua relevância ecológica, sobretudo quando constatada uma mudança significativa no padrão de uso desse frágil conjunto de macrohabitats.

No caso específico do Pantanal, a falta de um marco regulatório federal, embora relevante, não justifica a omissão dos governos, federal e estadual, na execução de ações básicas de gestão, ignorando que estamos diante de "uma riqueza que, de resto, deve ser preservada a qualquer custo, independentemente da existência de governantes e tecnocratas insensíveis e cooptantes com a predação". ${ }^{14}$

Como exemplo da omissão do poder público, cabe registrar a inexistência de uma política de unidades de conservação que considere as necessidades do Pantanal e de outras áreas úmidas no Brasil. Especialmente no Pantanal, apenas 5\% desse conjunto de ecossistemas, que é considerado um santuário ecológico, está protegido como unidade de conservação.

A maior parte dos problemas que afetam o Pantanal Mato-grossense é comum aos demais ecossistemas similares e superá-los requer, sobretudo, a vontade política e o compromisso dos cidadãos com esse objetivo. Sem a conjugação desses fatores a proteção do Pantanal Mato-grossense e demais áreas úmidas no Brasil parece longe de se concretizar.

Nessa tarefa, um passo significativo que pode revelar a vontade política e assegurar mobilização dos stakeholders com interesses sobre essas áreas é, certamente, a construção de um marco regulatório que assegure a proteção e promova a gestão das zonas úmidas do Brasil, envolvendo estratégias mais amplas de gestão, para ambientes tão complexos e diversificados, o que deve incluir uma política de gestão efetiva da bacia e remuneração por serviços ecossistêmicos entre outros instrumentos.

$\mathrm{Na}$ tarefa de construir esse marco regulatório, apoiar e monitorar a gestão dessas áreas, as universidades e centros de pesquisa devem exercer um protagonismo visando agregar interesses muitas vezes antagônicos em prol de uma causa maior, em benefício não apenas das gerações presentes.

14 AB'SÁBER, A. N. Brasil: Paisagens de exceção. O litoral e o Pantanal Mato-grossense. Cotia-SP: Atelie Editorial, 2006, p. 58. 


\section{Referências}

AB'SÁBER, A. N. Brasil: Paisagens de exceção. O litoral e o Pantanal Mato-grossense. Cotia-SP: Atelie Editorial, 2006.

AMANCIO, C. O. da G.; ARAUJO, M. T. B. D.; SANTOS, S. A.; NARCISO, M. G.; OlIVEIRA, M. D. Protocolo: Índice de Bem-Estar Social (IBS) para a Fazenda Pantaneira Sustentável (FPS). Disponível em: https://www.embrapa.br/pantanal/busca-de-publicacoes/-/publicacao/1054996/ protocolo-indice-de-bem-estar-social-ibs-para-a-fazenda-pantaneira-sustentavel-fps.

BENJAMIN, A. H. V. O Estado Teatral e a Implementação do Direito Ambiental. In: $7^{\circ}$ CONGRESSO INTERNACIONAL DE DIREITO AMBIENTAL. Anais... São Paulo: Imprensa Oficial, 2003. v.1.

BRASIL. Decreto n. 1.905, de 16 de maio de 1986. Promulga a Convenção sobre Zonas Úmidas de Importância Internacional, especialmente como Habitat de Aves Aquáticas, conbecida como Convenção de Ramsar, de 2 de fevereiro de 1971. Disponível em: < http://www.planalto.gov. br/ccivil 03/decreto/1996/D1905.htm > Acesso em: 13 jun. 2014.

. MMA/IBAMA. Monitoramento do desmatamento nos biomas brasileiros por satélite. Acordo de Cooperação Técnica. Centro de sensoriamento Remoto - CSR/IBAMA, 2011. Disponível em: <www.siscom.ibama.gov.br> Acesso em: 30 abr. 2014.

CALHEIROS, D. Querem mesmo acabar com o Pantanal! Disponível em: < http://www.viomundo. com.br/denuncias/o-dia-em-que-o-rio-secou.html > Acesso em: 30 mai. 2014.

CUNHA, Cátia Nunes da; PIEDADE, Maria Teresa F; JUNK, Wolfgang J. Classificação e delineamento das áreas úmidas brasileiras e de seus macrohabitats. Cuiabá: EdUFMT, 2015.

DALEY, R.; ZARULL, M.; MAYFIELD, C. A Suggested "Template" for Case Study Preparation. In: CONFERÊNCIA MANAGING SHARED WATERS, em Hamilton, Canadá, junho/2002.

DA SILVA, C. J.; SILVA SOUSA, K. N.; IKEDA-CASTRILLON, S. K.; LOPES, C. R. A. S.; DA SILVA NUNES, J. R.; CARNIELLO, M. A.; MARIOTTI, P. R.; LAZARO, W. L.; MORINI, A.; ZAGO, B. W.; FAÇANHA, C. L.; ALBERNAZ-SILVEIRA, R.; LOUREIRO, E.; VIANA, I. G.; OLIVEIRA, R. F.; ALVES DA CRUZ, W. J.; DE ARRUDA, J. C.; SANDER, N. L.; DE FREITAS JUNIOR, D. S.; PINTO, V. R.; DE LIMA, A. C.; JONGMAN, R. T. H. G. Biodiversity and its drivers and pressures of change in the wetlands of the Upper Paraguay-Guaporé Ecotone, Mato Grosso (Brazil). Land Use Policy, v. 47, p. 163-178, 2015.

DIEGUES, A. C. (Org.). Povos e Águas: inventário de áreas úmidas brasileiras. 2. ed. São Paulo: Nupaub-Usp, 2002.

DORES, Eliana F.; CALHEIROS, Débora F. Contaminação por agrotóxicos na bacia do rio Miranda, Pantanal (MS). Revista Brasileira de Agroecologia, v. 3, Suplemento especial, p. 202/205, 2008.

IRIGARAY, C. T. J. H. Áreas Úmidas especialmente "des' protegidas no Direito Brasileiro: O caso do Pantanal Mato-Grossense e os Desafios e Perspectivas para sua conservação. Revista de Estudos Sociais, Cuiabá, UFMT, v. 17, n. 34, 2015.

IRIGARAY, C. T. J. H.; SILVA, C. J.; MEDEIROS, H. Q.; GIRARD, P.; FAVA, G. C.; MACIEL, J. C.; GALLO, R.L.; NOVAIS, L. G. O Pantanal Matogrossense enquanto patrimônio nacional no contexto das mudanças climáticas. In: SILVA, Solange T., CUREAU, Sandra; LEUZINGER, M. (Org.). Mudança do Clima. Desafios jurídicos, econômicos e socioambientais. 1. ed. São Paulo: Fiuza, 2011.

IRIGARAY, C. T. J. H.; SOUZA, S. C. Os marcos regulatórios no Brasil: uma abordagem histórica crítica - a proteção jurídica do pantanal de Mato Grosso. In: SANTOS, J. E.; GALBIATI, C. (Org.). Gestão e Educação Ambiental: Água, Biodiversidade e Cultura. 1. ed. São Carlos: RIMA, 2008. v. 1. 
JUNK, W. J.; DA SILVA, C. J. O conceito de pulso de inundação e suas implicações para o pantanal de Mato Grosso. In: II SIMPÓSIO SOBRE RECURSOS NATURAIS E SOCIOECONÔMICOS DO PANTANAL: MANEJO E CONSERVAÇÃO, Corumbá: MS, 1996. Anais... Brasilia, Embrapa - CPAP.

MILARÉ, E. Direito do ambiente: Doutrina - prática - jurisprudência - glossário. São Paulo: RT, 2012. MIRANDA, Kelber; CUNHA, Marcelo L.; DORES, Eliana F.; CALHEIROS, Débora F. Pesticide residues in river sediments from the Pantanal Wetland, Brazil. Journal of Environmental Science and Health Part B, n. 43, 717-722, 2008. Disponível em: < http://ainfo.cnptia.embrapa.br/digital/bitstream/ item/105414/1/56722.pdf > Acesso em: 25 out. 2016.

MORIN, E.; KERN, A. B. Terra-Pátria. Trad. Paulo Neves. Porto Alegre: Sulina, 1995.

OST, F. A natureza à margem da lei: a ecologia à prova do direito. Trad. Joana Chaves. Lisboa: Instituto Piaget, 1995.

PETRY, Paulo; RODRIGUES, Sidney et al. Análise de Risco Ecológico da Bacia do Rio Paraguai: Argentina, Bolívia, Brasil e Paraguai. The Nature Conservancy; WWF-Brasil. Brasilia, DF: The Nature Conservancy do Brasil, 2011.

SANTINI, Daniel. Soja e gado agravam desmatamento do Chaco no Paraguai. Artigo publicado no Portal OECO em 22/08/14. Disponível em: < www.oeco.org.br > Acesso em: 22 ago. 2014.

SANTOS, J. R. Avanços das pesquisas e aplicações de sensoriamento remoto no monitoramento da paisagem: contribuições aos estudos do Pantanal. In: SIMPÓSIO DE GEOTECNOLOGIAS NO PANTANAL, Campo Grande, Brasil, 2006. Anais... Embrapa Informática Agropecuária/INPE, 2006. p. 675-683.

SANTOS, S. A. et al. A fuzzy logic-based tool to assess beef cattle ranching sustainability in complex environmental systems. Journal of Environmental Management, v. 198, p.95-106, 2017.

SERAFINI, L. Z. Proteção jurídica das áreas úmidas e os direitos Socioambientais. Dissertação (Mestrado em Programa de Pós-Graduação em Direito)- PUC-PR, Curitiba, 2007. Disponível em: < http://www.dominiopublico.gov.br/download/teste/arqs/cp024867.pdf $>$ Acesso em: 25 out. 2016.

SILVA, C. J.; NUNES, J. R. S.; SIMONI, J. O sistema de Báas Chacororé - Sinhá Mariana. In: SILVA, C. J.; SIMONI, J. (Orgs.) Água, biodiversidade e cultura do Pantanal: estudos ecológicos e etnobiológicos no sistema de Baías Chacororé - Sinhá Mariana. Cáceres: Ed. Unemat, 2012.

TNC/WWF. The Nature Conservancy; WWF-Brasil. Análise de risco ecológico na Bacia do Rio Paraguai-Argentina, Bolivia, Brasil e Paraguai. 1. ed. Bras1ia: 2012. 